\title{
EDUCA \& AÇÃO! LEVANDO A PRÁTICA AOS ACADÊMICOS DE ENGENHARIA CIVIL NO ENSINO REMOTO UTILIZANDO UM JOGO SÉRIO COMO METODOLOGIA ATIVA
}

\author{
Daniel Alves dos Santos ${ }^{1}$ \\ Gustavo Yuji Ito ${ }^{2}$ \\ Pedro Ignácio Meneghetti Scheid ${ }^{3}$ \\ Héllica Machado Barbosa ${ }^{4}$ \\ Kaio Henrique Pires da Silva ${ }^{5}$ \\ Virley Lemos de Souza ${ }^{6}$
}

RESUMO: Competências gerenciais são fundamentais para absorção no mercado de trabalho, porém o aluno de engenharia civil possui carga horária fundamentalmente teórica, contrariando a aprendizagem do engenheiro, já que 70\% de sua formação vem com experiências práticas, $20 \%$ por meio da interação com profissionais colegas e apenas Io\% das formas teóricas. Diante desse cenário, é preciso levar a prática até a graduação do aluno, e as metodologias ativas são uma opção para isso. As metodologias ativas colocam o acadêmico como figura central de sua aprendizagem, deixando a ideia da passividade do aluno em relação ao seu processo de aprendizagem. Existem várias metodologias ativas, mas, como já é aplicado nas empresas, os serious games são uma forma de desenvolver competências ao mesmo tempo que leva as estratégias do mercado de trabalho à graduação. Um jogo sério baseado no RPG (RPG) Educa \& Ação! foi desenvolvido, o qual é totalmente adaptável às disciplinas, tanto no tema como na duração e aplicação. Idealizado inicialmente para a educação presencial, o Educa \& Ação! foi repensado para a realidade do ensino a distância, e uma nova validação foi feita com alunos de engenharia civil que já cursaram ou estão cursando a disciplina de Planejamento e Gestão de Obras. O resultado do feedback foi positivo: Ioo\% acreditam que o Educa \& Ação! é uma ferramenta que contribui para a sua formação, o Educa \& Ação! desenvolve soft skills dos jogadores, I00\% jogariam novamente e I00\% se divertiam jogando.

Palavras-chave: Habilidades gerenciais. Soft skills. Metodologia ativa. Serious game. Ensino remoto.

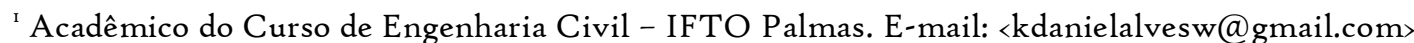

${ }^{2}$ Acadêmico do Curso de Engenharia Civil - IFTO Palmas. E-mail: <gustavo.yuito@gmail.com>

${ }^{3}$ Graduado em Engenharia Civil - IFTO Palmas. E-mail: <p.scheid22@gmail.com>

${ }^{4}$ Acadêmica do Curso de Engenharia Civil - IFTO Palmas. E-mail: <hellica_machado@hotmail.com〉

${ }^{5}$ Acadêmico do Curso de Engenharia Civil - IFTO Palmas. E-mail: <kaiohp.silvar@gmail.com>

${ }^{6}$ Doutor em Construção Civil com ênfase em Gestão (UnB), MESTRE em Estruturas e Construção Civil com foco em Gestão e Planejamento (UnB). Possui ESPECIALIZAÇÕES em nível lato sensu nas seguintes formações: Gestão e Auditoria na Administração Pública (FALBE); Agente de Inovação e Difusão Tecnológica (ABIPT/UFT), Educação Profissional Integrada à Educação Básica (IFTO), Saneamento e Meio Ambiente (FTB). Professor do Curso de Engenharia Civil - IFTO Palmas. E-mail: <virley@ifto.edu.br>
} 
ABSTRACT: Managerial skills are fundamental for absorption in the job market, but the civil engineering student has a fundamentally theoretical workload, going against the proportion of the engineer learning, since $70 \%$ of his training comes with practical experiences, $20 \%$ through interaction with professional colleagues and only 10\% of theoretical forms. Taking this scenario into account, it is necessary to take the practice to the student's graduation, and active methodologies are an option for that. Active methodologies place the academic as the central figure of their learning, leaving the idea of the student's passivity regarding their learning process. There are several active methodologies, but, since it is already applied in companies, serious games are a way to develop skills while taking the strategies of the labor market to graduation. A serious game based on the role-playing game (RPG) called Educa \& Ação! was developed, which is completely adaptable to the disciplines, both in theme and in duration and application. Initially designed for face-to-face education, Educa \& Ação! it was rethought for the reality of remote education, and a new validation was made with civil engineering students who have already studied or are studying the discipline of Planning and Construction Management. The results of the feedback were positive: Ioo\% believe that Educa \& Ação! is a tool that contributes to your education, Educa \& Ação! develops soft skills of the players, I0o\% would play again and $100 \%$ had fun playing.

Keywords: Management skills. Soft skills. Active methodology. Serious game. Remote teaching.

\section{INTRODUÇÃO}

Com a formação de cada vez mais engenheiros civis, o mercado de trabalho vem exigindo mais do que a formação curricular padrão dos profissionais, dando prioridade e retenção aos profissionais capazes de compreender holisticamente o processo de tomada de decisão. Segundo o Project Management Institute (2017), abreviado como PMI, o gerente de projetos não é somente responsável pelo projeto em si, mas também pelas equipes que o compõem, necessitando de conhecimentos e habilidades técnicas inerentes ao tipo de projeto e também interpessoais, como as soft skills. E para o profissional desenvolver habilidades gerenciais, é necessário que ele seja submetido a um ambiente de experiências práticas o mais próximas possíveis da realidade.

Lombardo e Eichinger (1996), citando uma pesquisa do Center for Creative Leadership (CCL), expuseram o conceito 70-20-Io, que representa a proporção de aprendizagem com 70\% vindo da prática, $20 \%$ de troca de experiências entre colegas e $10 \%$ do ensino formal, como livros e aulas. Os cursos de engenharia vão na direção contrária, tendo a carga horária teórica como a maior porcentagem, gerando uma inconsistência entre os profissionais recém-saídos da faculdade e os absorvidos pelo mercado de trabalho.

Um ensino tradicional, onde as aulas ministradas colocam o professor como detentor do conhecimento e o acadêmico como receptor, torna o aluno um agente passivo no seu próprio ensino (SOUZA E DOURADO, 2015), o que projeta um futuro profissional também passivo, intrinsecamente o oposto ao exigido pelo mercado de trabalho. A capacidade de colocar o acadêmico no centro da aprendizagem, tornando-o cada vez mais independente no seu processo de formação (DIESEL et al. 2017) é o que vem popularizando o estudo e uso de metodologias ativas. 
De acordo com Moraes e Cardoso (2018), visando tornar o estudante o responsável pelo desenvolvimento de suas próprias competências, vem-se absorvendo e adotando novas ferramentas de ensino. E Gadioli et al. (2012) afirmam que o foco dos professores deve ser estratégias de ensino que levem à sala de aula um contexto calcado o mais próximo possível da realidade, construindo situações de aprendizagem críveis.

Para diminuir o gargalo entre academia e mercado de trabalho, é preciso levar as metodologias ativas de aprendizado que o mercado utiliza com seus funcionários para a graduação. O jogo sério é uma das alternativas, tendo como objetivo desenvolver competências nos seus jogadores, mas contando com uma complexidade para o desenvolvimento. Para contornar essa dificuldade de implementação do jogo sério, foi pensado um modelo que se adapte a todas as disciplinas, excluindo a necessidade de pensar por completo um novo jogo sempre que o tema for alterado. Esse modelo de jogo sério foi batizado de Educa \& Ação!

Pensado, executado e validado inicialmente como jogo analógico aplicado presencialmente, o Educa \& Ação!, assim como as aulas e outras metodologias ativas que compartilham dessa modalidade, teve sua aplicação impossibilitada na realidade do ensino remoto. Então é preciso adaptar suas mecânicas e jogabilidade ao novo padrão de aulas.

E por que ter todo esse trabalho para levar a prática ao estudante? Moraes e Cardoso (2018) justificam que pelo aumento da complexidade e dos custos dos projetos de construção, são precisos mais profissionais capacitados para geri-los. O conhecimento técnico já não é mais suficiente, tornando a capacidade de tomada de decisões eficientes e eficazes frente aos desafios da profissão um ponto chave para o profissional.

\section{PERCURSO METODOLÓGICO}

\section{I.I Metodologias Ativas}

Segundo Moran et al. (2017), metodologias ativas podem ser definidas como estratégias de ensino centradas na participação efetiva dos estudantes na construção do processo de aprendizagem, de forma flexível, interligada, híbrida.

As metodologias ativas constituem como alternativas pedagógicas que colocam o foco do processo de ensino e de aprendizagem no aprendiz, esse envolvimento gera a aprendizagem por descoberta, investigação ou resolução de problemas. Essas metodologias contrastam com a abordagem pedagógica do ensino tradicional centrado no professor, que é quem transmite a informação aos alunos (VALENTE, 2018).

Tradicionalmente as metodologias ativas têm sido implementadas por meio de diversas estratégias, como a aprendizagem baseada em projetos (project-based learning - PBL); a aprendizagem por meio de jogos (game-based learning - GBL); o método do caso ou discussão e solução de casos (teaching case); e a aprendizagem em equipe (team-based learning - TBL), porém ele indica a dificuldade para com essa abordagens a adequação dos conteúdos curriculares previstos para o nível de conhecimento e de interesse dos alunos (VALENTE, 2018).

Um método de aprendizado passivo entendido como leitura, pesquisa, escuta e observação proporciona a um acadêmico que fica exposto a informação de forma passiva tem uma retenção de conhecimento entre $20 \%$ e $50 \%$, se esse mesmo conhecimento for adquirido exclusivamente por leitura ele não consegue reter 10\% das informações. Ao ser exposto a um método de aprendizado ativo como diálogo, prática e ensino, a retenção de conhecimento fica na faixa de 70\% a 95\% de retenção de informação (EDUPULSES, 2021a). 
A gamificação é o processo de utilização do pensamento, dinâmica e elementos de jogos para o engajamento de pessoas na resolução de problemas. Ou seja, é a utilização de técnicas de games para tornar as atividades mais divertidas e promover a aprendizagem, trazendo à tona o desejo de colaborar e compartilhar experiências levando as pessoas a desenvolver habilidades, alterar comportamentos e aprimorar saberes e conhecimentos (EDUPULSES, 2021b).

Alves et al. (2014) afirmam que a gamificação se constitui na utilização da mecânica dos games em cenários non games, levando a criação de espaços onde a aprendizagem é mediada pelo desafio, pelo prazer e entretenimento. induzindo a compreensão dos espaços de aprendizagem como distintos cenários escolares e não escolares que potencializam o desenvolvimento de habilidades cognitivas (planejamento, memória, atenção, entre outros), habilidades sociais (comunicação assertividade, resolução de conflitos interpessoais, entre outros) e habilidade motoras.

De acordo com Domínguez et al. (2012), os jogos podem prover um contexto ficcional sob a forma de narrativas, imagens e sons, que, se usados apropriadamente, podem funcionar como tópicos de aprendizado, o que fica caracterizado como método de aprendizado ativo. Furió et al. (2013) afirma que o ato de jogar além de ser uma atividade prazerosa serve como um meio de desenvolver habilidades através das tarefas realizadas. Esse ato pode ser utilizado como ferramenta para desenvolver habilidades de cognição, além de apresentar exemplos de aprendizado e estimular a atenção e memória.

\subsection{Jogos Sérios}

A construção da definição de jogos sérios, do inglês serious games, perpassa, em um primeiro momento, pelo entendimento das características que um jogo possui e o seu grande potencial como uma ferramenta de metodologia ativa. Inicialmente, surgem as definições de Abt (1970) as quais são focadas na discussão de como os jogos possibilitam os jogadores na busca de objetivos dentro das possibilidades de regras existentes, complementando que eles oferecem uma gama enorme de possibilidades, sendo caracterizados pelo sentimento de liberdade, estímulo de intuição rápida e desenvolvimento da cooperatividade dentro de um modelo que pode ser inspirado pelo mundo real. Susi (2007) complementa que, uma vez criados para o entretenimento, os jogadores mantêm seu foco na diversão e na satisfação enquanto jogam. Essa questão é retomada por Novak (2010) quando explica que os jogos são focados no entretenimento e apresentam as seguintes características: regras, estratégias, desafios e recompensas.

Nesse sentido, com o aparecimento de problemáticas educacionais e sociais, urge a necessidade de ferramentas que auxiliem o processo de ensino-aprendizagem. $O$ desenvolvimento da tecnologia abriu as portas para que os jogos surgissem como uma opção para vencer tais problemáticas. Para tanto, seria necessário que o entretenimento deixasse de ser o aspecto principal, e é nesse contexto que começam a surgir as definições de jogos sérios. Inicialmente, o acréscimo da palavra "sérios" pode trazer uma oposição ao termo "entretenimento". Abt (1970) discorre que o termo "sério" evoca o senso de estudo relacionado a assuntos de grande relevância, levantando problemáticas, questões e principalmente, resoluções para estas. Por outro lado, o autor ressalta que, mesmo incorporando ao jogo um objetivo com certa seriedade relacionada ao mundo real, ele não perde sua essência no que tange a diversão e entretenimento.

O autor então desenvolve o conceito de jogo sério como sendo este que trará situações analíticas sobre uma problemática ou um objetivo em comum ao mesmo tempo em que permite a liberdade intuitiva e a criatividade do jogador. De uma forma mais direta, Oliveira (2016) 
define que os jogos sérios tem como objetivo ensinar/treinar além de prover entretenimento. Assim sendo, como complementa Raessens (2010), os jogos sérios são usados para lidar com temas relevantes para a sociedade, objetivando efeitos para além do jogo, tanto no mundo real quanto na individualidade do jogador, e dessa forma, desenvolve novos conhecimentos e novas habilidades para ele, como declara Corti (2006).

Um dos aspectos mais importantes que Zyda (2005) salienta nos jogos sérios é a pedagogia. Ela, na criação de jogos sérios, incorpora elementos que educam e instruem transmitindo conhecimentos e habilidades. E nesse sentido, o autor complementa que um jogo sério é uma competição mental complementada pelo entretenimento que poderá ser utilizada para treinamento educacional em corporações, universidades, setores de saúde e políticos, entre outros.

Para a aplicação de um jogo sério, Zyda (2005) elenca três tipos de atores: a equipe técnica, o usuário final de domínio e o usuário aprendiz. A equipe técnica será responsável por desenvolver o jogo. Nessa criação, a equipe deve ser muito precisa para simular o contexto em questão estudando as diversas possibilidades existentes a fim de alcançar o objetivo desejado. $\mathrm{O}$ usuário final de domínio serão os especialistas que farão a aplicação do jogo e avaliarão o usuário aprendiz, aqueles que efetivamente serão os jogadores.

$\mathrm{Na}$ etapa de criação é fundamental que o jogo sério contenha determinadas características. Aprofundando o conceito de jogos sérios, Rocha, Bittencourt e Isotani (2015) elencam alguns requisitos e características que devem estar presentes no desenvolvimento do jogo. Ser um objeto de aprendizagem, treinamento e avaliação através de um software de simulação são uns dos principais requisitos que o autor destaca. Também Novak (2010) traz elementos como regras, estratégias, desafios, recompensas, níveis e feedback contínuo além de fidelidade física, comportamental e psicológica do que está sendo simulado, também comentado por Goldsman (2007). Esses elementos devem ser profundamente estudados pela equipe técnica na etapa de desenvolvimento.

$\mathrm{Na}$ etapa de aplicação, é fundamental que o usuário final de domínio, ou seja, os especialistas que farão a aplicação do jogo sério, garantam a aplicação das competências requeridas bem como a análise de desempenho por parte dos aprendizes. Zyda (2005) sugere que, na fase de aplicação, os especialistas devem determinar o que acontece durante o jogo e também como este afeta os aprendizes. Para potenciar esse processo, o autor explicita que, para os monitores, adquirir uma capacidade de análise e um entendimento quase que automático sobre a realidade simulada gerará um relatório de alto nível. Tal relatório é fundamental para alcançar os objetivos desejados por parte do usuário final de domínio.

Do ponto de vista do usuário aprendiz, sabendo que a realidade simulada proporciona liberdade de tomada de decisões sem oferecer maiores riscos, estes se sentem motivados a enfrentar problemas, elaborar estratégias, tomar decisões e assumir as consequências ger adas por elas. Dessa forma, os jogos sérios possibilitam aos aprendizes uma melhor preparação para o cenário real.

Assim, como mostra Zyda (2005) e Abt (1970) setores da educação, setores governamentais e empresariais, defronte as possibilidades e aplicabilidades dos jogos sérios, vem aplicando-os cada vez mais nas suas atividades de competência. Na educação englobando estudos sociais, comunicação e ciências, por exemplo; no setor empresarial auxiliando em controle financeiro, gestão de pessoas e decisões mercadológicas; e até mesmo em treinamentos especializados de setores governamentais especializados, como os militares. 


\subsection{Educa \& Ação!}

O Educa \& Ação! é um jogo que foi desenvolvido baseado no gênero chamado role-playing game (RPG), que é comumente traduzido como "jogo de interpretação de papéis". Jogos desse gênero têm como principais elementos a criatividade e a cooperatividade (GRANDO E TAROUCO, 2008), e por isso em sua maioria são jogados em grupos em torno de três a seis pessoas.

Para continuar, é de suma importância entender como é a mecânica narrativa padrão do RPG, que, seguindo a descrição de Grando e Tarouco (2008), um dos jogadores, chamado de Narrador, guia a história como se fosse um diretor de um filme, enquanto o restante dos participantes são os protagonistas dessa história que de forma ativa e em conjunto com o Narrador vão desenvolvendo a narrativa do jogo.

Nessas características é comum pensar então que o professor, ao aplicar um jogo RPG em uma turma de alunos, faria o papel de Narrador, enquanto os estudantes são os personagens. Porém, em uma turma de 30 a 40 alunos, é inviável para o professor desenvolver o papel de Narrador para todos esses jogadores e por isso foi utilizado um estilo de RPG onde a figura do Narrador é compartilhada por todos os jogadores, ou seja, todos os estudantes narram e são personagens inseridos na história.

Com essa estrutura do RPG, a aplicação do jogo dentro de uma turma de alunos se torna mais plausível, onde o professor possui um papel de supervisão e gerenciamento dos grupos de alunos, enquanto todo o processo criativo e narrativo das histórias parte dos estudantes. Esse ponto corrobora e incentiva o desenvolvimento de soft skills, haja vista que trabalha relações pessoais interpessoais, além de simular os $70 \%$ de ensino prático e trabalhar os $20 \%$ de interação com os colegas.

Outro destaque é que enquanto um jogo criativo, narrativo e imaginário, o Educa \& Ação! possibilita ao professor uma flexibilização na escolha do tema principal da aplicação do jogo, podendo ser aplicado em variados conteúdos e disciplinas. Já houveram sessão de jogos com temas de planejamento de obras, gerenciamento de eventos, movimentos literários e mitologia grega. Além disso, o jogo pode durar mais ou menos tempo de acordo com a necessidade do professor, seguindo o tempo disponível do mesmo dentro de uma turma, relacionado proporcionalmente ao número de alunos em cada grupo.

\section{I.4 Ambiente Virtual}

Por conta da pandemia instaurada pelo coronavírus, SARS-CoV-2, que tem transmissão pelo toque de mãos, gotículas de saliva, espirros, tosse, objetos e superfícies contaminadas. Com I5\% das pessoas infectadas desenvolvendo sintomas graves e $5 \%$ forma crítica da doença (BRASIL, 2020). O distanciamento social é uma das formas de proteção, sendo um dispositivo para reduzir a interação das pessoas presencialmente, diminuindo a velocidade de transmissão. Em consequência da disseminação do coronavírus no mundo, as atividades, antes presenciais, agora são desenvolvidas de maneira virtual, escolas ofertando por ensino remoto, trabalhos de escritório para home office. Essa mudança do presencial para o virtual traz as necessidades de ambientes virtuais para que tenha interação e desenvolvimento de atividades.

$\mathrm{Na}$ aplicação do Educa \& Ação! online, surgiu a necessidade de uma plataforma para a criação do ambiente virtual que proporciona as ferramentas para o funcionamento do jogo, como comunicação rápida e interativa, rolagem de dados e gravação de voz. Em meio às tecnologias para reuniões online, o Discord se destacou por ser uma plataforma gratuita e acessível. 
O Discord é um programa de conversas por texto, áudio e vídeo criado originalmente para utilização durante jogos onlines, disponível em vários sistemas operacionais: Microsoft Windows, macOS, iOS, Android, Linux e em navegadores de internet. Permite a criação de canais de texto, canais de voz, realização de conversas com várias pessoas simultaneamente, compartilhamento de tela e vídeo chamadas. Tendo a sua organização por servidores, que é ambiente virtual, o acesso se dá por meio de link de convites.

Os servidores no Discord são um espaço com várias camadas de configurações. É possível abrir vários canais de texto e de voz, controlar os níveis de acesso por cargos, adicionar bots que efetuam ações por comandos. Bots são softwares externos, criados por terceiros, que adicionam novas funcionalidades ao servidor em que é inserido.

Para a execução do jogo Educa \& Ação! de forma online, foi criado um servidor no Discord com acesso por meio de um link compartilhável, que conta com chat geral para anúncios, chat para tirar dúvidas, um canal de voz lobby para socialização, dez salas com canal de texto e voz para jogadores, separadas do grupo i ao grupo ı, e sala de interação dos administradores para reuniões internas. Cargos com controle de acesso para administradores, jogadores, professores e de manipulação dos bots. Foram inseridos no servidor três bots, sendo o rollem para rolagem de dados, Craig para a gravação de voz unificada das sessões de jogos e MEE6 para gerenciamento geral do servidor. A fim de facilitar o acesso dos acadêmicos e professores, foi criado um vídeo tutorial de como se registrar, usar o Discord e um exemplo do jogo Educa \& Ação! que disponibilizado na plataforma do YouTube.

\section{RESULTADOS E DISCUSSÃO}

O Educa \& Ação! já foi testado presencialmente, em matérias como planejamento e gerenciamento de obras e gestão de qualidade. O sucesso foi comprovado com os trinta alunos que participaram. Um total de $96,7 \%$ dos acadêmicos acreditou que o Educa \& Ação! é uma ferramenta que pode contribuir para sua formação, 93,3\% dos alunos que jogariam novamente e I00\% se divertiu jogando. Foi realizado um teste amostral com sete alunos que estão cursando ou já cursaram a matéria de planejamento e gerenciamento de obra, repetindo o mesmo jogo do presencial, mas melhorado.

Durante os jogos, foram jogados um jogo com três e outro com quatro acadêmicos e todos entraram no Discord sem problemas. Com o primeiro grupo, foi notada uma dificuldade na primeira rodada para inserir seu personagem, dificuldade essa que não houve no segundo grupo.

Após a aplicação, foi enviado um questionário online para os participantes, e as respostas foram em relação ao desenvolvimento de soft skills, a contribuição para formação dos estudantes, repetibilidade do jogo e, por ser um jogo, o aspecto lúdico importante que é a diversão.

Figura I - Respostas sobre desenvolvimento de soft skills

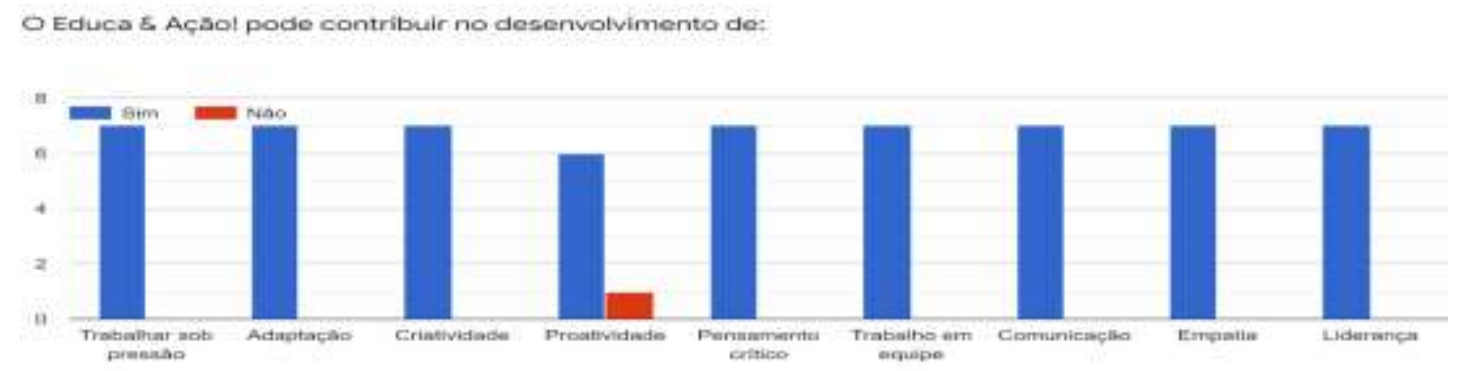

Fonte: Autores (2021) 
Figura 2 - Respostas sobre a contribuição na formação

Educa $\&$ Ação! pode contribuir para a formação dos estudantes? 7 respostas

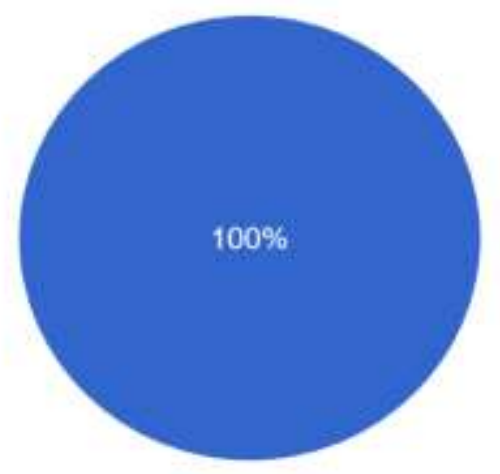

- $\operatorname{sim}$

- Năo

Fonte: Autores (2021)

Em relação à contribuição na formação dos estudantes, na Figura 2, 100\% dos alunos afirmaram que o Educa \& Ação! é capaz de auxiliar na formação dos acadêmicos de engenharia civil, que pode ser validada pelas respostas na Figura I, onde os alunos concordam que o Educa \& Ação! desenvolve as soft skills elencadas, comprovando que o jogo pode ser aplicado mesmo em ambiente virtual.

Figura 3 - Respostas sobre o fator repetição do jogo

\section{Você jogaria novamente o Educa \& Ação! ?}

7 respostas

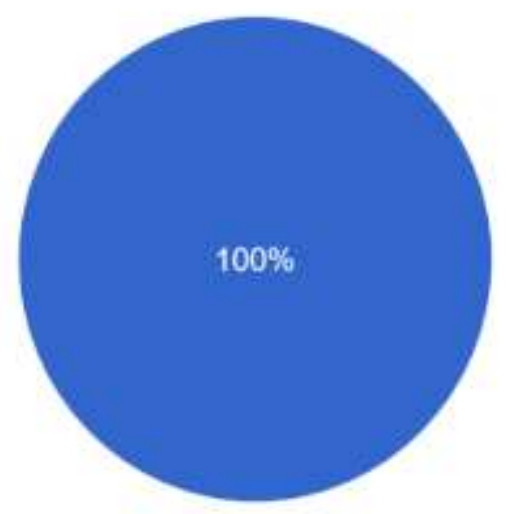

Fonte: Autores (2021) 
Figura 4 - Respostas sobre a diversão dos estudantes

\section{Você se divertiu?}

7 respostas

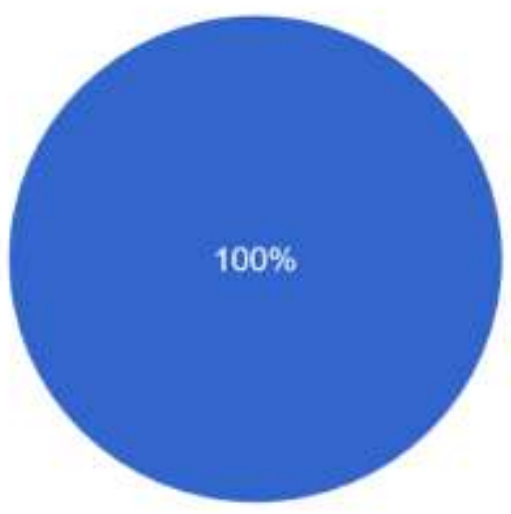

Sim

Não

Fonte: Autores (2021)

Outro ponto que foi levado em consideração é o fator de repetição do jogo, que de acordo com a Figura 3, todos os estudantes aceitariam jogar o Educa \& Ação! novamente, e correlacionando com um aspecto que é de suma importância sua avaliação quando se trata de jogos, a capacidade de divertir o jogador, destacado pela Figura 4 onde $100 \%$ dos alunos se divertiram durante a dinâmica. Finalizando com uma experiência geral dos alunos de 9,85, dentro de uma escala de o a Io, onde o é uma má experiência e ıo uma ótima experiência.

Os acadêmicos aprovaram o material, classificando-o como claro, e o tutorial, que serviu para explicar melhor o jogo. Eles também mostraram desejo de jogar novamente, pois a interação divertida com os colegas foi de grande agrado, mas não deixaram de lado os comentários sobre a responsabilidade e a empatia necessária na interpretação, sendo colocados como personagens que não serão posteriormente, como mestre de obra, mas que lidarão no decorrer da carreira.

\section{CONCLUSÃO}

O Educa \& Ação! mostrou-se uma metodologia eficiente ao ser aplicado online, com o uso do ambiente virtual para interação dos jogadores. O Discord ofereceu as ferramentas necessárias de forma simples aos acadêmicos, não quebrando o ritmo do jogo graças à disponibilidade do tutorial de forma prévia, resultando com que jogo tivesse um tempo de aplicação de quarenta e cinco minutos, ficando dentro do tempo padrão de uma aula, que é entre cinquenta minutos e uma hora.

Ao jogar na primeira rodada do jogo, foi notado um tempo de adaptação para se habituar ao processo de narrar as ações de um personagem e absorver a dinâmica do jogo. Percebe-se que na rodada seguinte, os jogadores já interpretam com um melhor ritmo e dinâmica de grupo. É indicado dar aos acadêmicos um roteiro de como agir durante a cena no primeiro contato com o 
jogo, composto das seguintes perguntas: o que você vai fazer? Por que você vai fazer? Como você vai fazer? Rola o dado. O que deu certo ou deu errado baseado no dado? Por que deu certo ou errado? $\mathrm{E}$ as consequências do resultado.

Os acadêmicos consideram que o Educa \& Ação! desenvolve de forma quase unânime as nove soft skills elencadas. Essas são habilidades exigidas para a inserção no mercado de trabalho que é cada vez mais competitivo. $O$ fato do aluno exercer um papel com funções a cumprir e ter que resolver as situações abordadas, passando pelos empecilhos e imprevistos o faz trabalhar sob pressão, se adaptar à história e ações dos colegas, ser criativo e proativo para resolver os problemas com pensamento crítico, não esquecendo o trabalho em equipe e uma boa comunicação com o colega, gerando empatia e liderança.

Conclui-se que o Educa \& Ação! é um jogo sério utilizado como metodologia ativa resiliente às adaptações do ensino remoto, que desenvolve competências e soft skills dos acadêmicos enquanto os faz revisitar o conteúdo de forma mais aplicada, crível e, o mais importante, divertida.

\section{AGRADECIMENTOS}

Aos nossos colegas que participaram do teste do Educa \& Ação!

À estudante Maria Clara, por nos ajudar no projeto.

\section{REFERÊNCIAS}

ABT, Clark C. Serious Games. University Press of America, New York, v. 2, 1987.

ALVES, Iynn Rosalina Gama et al. Gamificação: diálogos com a educação. In: FADEL, Luciane Maria et al (org.). Gamificação na educação. São Paulo: Pimenta Cultura, 2014. Cap. 6. p. I43-165. Disponível em: https://www.pimentacultural.com/gamificacao-na-educacao. Acesso em: o4 abr. 202I.

BRASIL. Ministério da Saúde. Sobre a doença. Brasília. 2020. Disponível em: https://coronavirus.saude.gov.br/index.php/sobre-a-doenca. Acesso em: 2I abr. 202I.

CORTI, K. Games-based Learning: a serious business application. PIXELearning Limited, 2006. Disponível

em: https://www.cs.auckland.ac.nz/courses/compsci777s2c/lectures/Ian/serious\%2ogames\%2obusi ness\%20applications.pdf. Acesso em: 03 abr. 2021.

DIESEL, Aline; BALDEZ, Alda Leila Santos; MARTINS, Silvana Neumann. Os princípios das metodologias ativas de ensino: uma abordagem teórica. Revista Thema, v. I4, n. I, p. 268288, 2017. Disponível em: http://periodicos.ifsul.edu.br/index.php/thema/article/view/404/295. Acesso em: 19 abr. 2021.

DOMÍNGUEZ, Adrián; NAVARRETE, Joseba Saenz de; MARCOS, Luis de; SANZ, Luis Fernández; PAGÉS, Carmen; HERRÁIZ, José Javier Martínez.

Gamifying learning experiences: Practical implications and outcomes. 
Journal Computers \& Education, Virginia, v. 63, p. 380-392, 2013. Disponível em:https://www.sciencedirect.com/science/article/abs/pii/So36or3151300oo3r. Acesso em: 04 abr. 2021.

EDUPULSES. Como a gamificação pode impactar o aprendizado?. In: Mês Das Metodologias Ativas, 2., 2021a. Disponível em: https://d335luupugsy2.cloudfront.net/cms\%2Ffiles\%2F75379\%2Fi615918657ARTIGO__COMO_A_GAMIFICAO_PODE_IMPACTAR_O_APRENDIZADO.pdf. Acesso em: 04 abr. 202I.

EDUPULSES. Gamificação: conceito e aplicação como ferramenta para resolução de problemas. In: Mês Das Metodologias Ativas, 2., 202rb. Disponível em: https://d335luupugsy2.cloudfront.net/cms\%2Ffiles\%2F 75379\%2Fi616521175ARTIGO__GAMIFICAO__CONCEITO_E_APLICAO_COMO_FERRAMENTA_PARA_RESOLUO_DE_PROBLEMA S_I.pdf. Acesso em: 04 abr. 202I

FURIÓ, David; GONZÁLEZ-GANCEDO, Santiago; JUAN, M. C.; SEGUÍ, Ignacio; COSTA, María. The effects of the size and weight of a mobile device on an educational game. Journal Computers \& Education, Virginia, v. 64, p.

24-4I, 2013. Disponível em:https://www.sciencedirect.com/science/article/abs/pii/So360131512003065.Acesso em: o4 abr. 202I.

GADIOLI, J. A. S. et al. O uso de jogo jit card como estratégia de ensino aprendizagem de serviços de manutenção industrial. In: XIX SIMPÓSIO DE ENGENHARIA DE PRODUÇÃO (SIMPEP), Anais... Bauru - SP, 2012.

GOLDSMAN, D. Introduction to Simulation. In: Winter Simulation Conference, Washington, DC. Piscataway: IEEE Press. 2007, p. 26-37.

GRANDO, Anita; TAROUCO, Liane Margarida Rockenbach. O uso de jogos educacionais do tipo RPG na educação. RENOTE-Revista Novas Tecnologias na Educação, v. 6, n. I, 2008.

LOMBARDO, M. M.; EICHINGER, R. W. The career architect development planner. Minneapolis: Lominger. 1996.

MORAES, Mônica Nogueira de; CARDOSO, Patrícia Alcântara. Jogos para ensino em engenharia e desenvolvimento de habilidades. João Pessoa, 2018. Disponível em: https://pdfs.semanticscholar.org/6oao/699db5ibi5b9072fb4a41oa6053a558857eb.pdf. Acesso em: I9 abr. 202I.

MORAN, José et al. Metodologias ativas e modelos híbridos na educação. In: YAESGASHI, Solange Franci Raimundo et al (org.). Novas Tecnologias Digitais: Reflexões sobre mediação, aprendizagem e desenvolvimento. Curitiba: Crv, 2017. p. 23-35. Disponível em: https://www2.unicentro.br/proen/files/2018/o8/Metodologias_Ativas.pdf. Acesso em: 04 abr. 202I. 
NOVAK, Jeannie. Game development essencials. Cengage Learning, 2017, 2ª ed.

OLIVEIRA, Helder, Cognaco; HOUNSELL, Marcelo da Silva; GASPARINI, Isabela. Uma Metodologia Participativa para o Desenvolvimento de Jogos Sérios. SBC - Proceedings of SBGames, São Paulo, 2016.

PROJECT MANAGEMENT INSTITUTE - PMI. Um guia do conhecimento em gerenciamento de projetos: Guia PMBOK, 6a. Ed. Project Management Institute, 2017.

RAESSENS, J. A Taste of Life as a Refugee: How Serious Games Frame Refugee Issues. Changes in Museum Practice: New Media, Refugees and Participation. Berghahn Books, 2010, p. 94-105.

ROCHA, Rafaela Vilela da; BITTENCOURT, Ig Ibert; ISOTANI, Seiji. Análise, Projeto, Desenvolvimento e Avaliação de Jogos Sérios e Afins: uma revisão de desafios e oportunidades. Anais do XXVI Simpósio Brasileiro de Informática na Educação (SBIE), 2015, Maceió. Anais. Maceió, 2015. Disponível em: http://www.brie.org/pub/index.php/sbie/article/download/5342/3705. Acesso em: 21 abr. 2019.

SILVA, Cláudio Henrique da et al. Design motivacional no processo de gamificação de conteúdos para objetos de aprendizagem: contribuições do modelo arcs. In: FADEL, Luciane Maria et al (org.). Gamificação na educação. São Paulo: Pimenta Cultura, 2014. Cap. 6. p. 143-ı65. Disponível em: https://www.pimentacultural.com/gamificacao-na-educacao. Acesso em: 04 abr. 2021.

SOUZA, Samir Cristino de; DOURADO, Luis. Aprendizagem baseada em problemas (ABP): um método de aprendizagem inovador para o ensino educativo. Holos, v. 5, p. 182-200, 2015. Disponível em: http://www2.ifrn.edu.br/ojs/index.php/HOLOS/article/view/288o. Acesso em: I9 abr. 202I.

SUSI, Tarja; JOHANNESSON, Mikael; BACKLUND, Per. Serious Games - an overview. Skövde: Institutionen för kommunikation och information, 2007, p. 28.

VALENTE, José Armando. A sala de aula invertida e a possibilidade do ensino personalizado: uma experiência com a graduação de midialogia. In: BACICH, Lilian et al (org.). Metodologias ativas para uma educação inovadora: uma abordagem téorico-prática [recurso eletrônico]. Porto Alegre: Penso, 2018. p. 77-108. Disponível em: https://curitiba.ifpr.edu.br/wpcontent/uploads/2020/o8/Metodologias-Ativas-para-uma-Educacao-Inovadora-Bacich-eMoran.pdf. Acesso em: 04 abr. 202I.

ZYDA, Michael. From Visual Simulation to Virtual Reality to Games. USC Information Sciences Institute, IEEE Computer Society, 2005. 